\section{Heart in acute pancreatitis: facts and fictions}

\author{
Raffaele Pezzilli, ${ }^{1}$ Bahjat Barakat, ${ }^{2}$ \\ Alessandra Barassi ${ }^{3}$ \\ 'Department of Digestive System, $\mathbf{S}$. \\ Orsola-Malpighi University Hospital, \\ Bologna; 2Department of Emergency, \\ S. Orsola-Malpighi University Hospital, \\ Bologna; ${ }^{3}$ Department of Health Sciences, \\ University of Milan - San Paolo Hospital, \\ Italy
}

\begin{abstract}
Pain is the hallmark of acute pancreatitis and it is localized in the epigastrium in more than $60 \%$ of patients having mild or severe disease. Acute pancreatitis may mimic other diseases such as acute coronary syndrome. In addition, the acute illness of the pancreas is associated with a number of metabolic abnormalities, such as hypocalcemia and hypophosphatemia, which may cause hemodynamic changes and variations in the concentration of ionized calcium. In turn, these have been directly correlated to changes in myocardial contractility. The aim of this paper is to review the current literature on the involvement of heart during the course of acute pancreatitis and also to evaluate experimental and clinical data on this topic.
\end{abstract}

\section{Introduction}

Pain is the hallmark of acute pancreatitis and it is localized in the epigastrium in more than $60 \%$ of patients having mild or severe disease. ${ }^{1}$ Sometimes acute pancreatitis may mimic other diseases and, in particular, acute coronary syndrome. ${ }^{2}$ In addition, the acute illness of the pancreas is associated with a number of metabolic abnormalities, such as hypocalcemia and hypophosphatemia which may cause hemodynamic changes and variations in the concentration of ionized calcium have been directly correlated to changes in myocardial contractility. ${ }^{3}$ Our aim is to review the current literature on the involvement of heart during the course of acute pancreatitis and to evaluate experimental and clinical data on this topic.

\section{Pathogenesis of acute pancre- atitis}

The main etiology of acute pancreatitis, at least in Western countries remains that of bil- iary origin. In fact, biliary forms represented the most frequent etiological category (69.3\%), while alcoholic forms occurred in only $6.6 \%$; all together the remaining etiologies (postsurgery, post-endoscopic cholangiopancreatography, traumatic, hyperlipemic, drug-induced and pancreas divisum) accounted for $7.1 \%$ of cases and $17.1 \%$ remained without a definite etiological factor. ${ }^{4}$ The current theory of acute biliary pancreatitis is the common bile duct obstruction, which increases pancreatic duct pressure that led to trypsin activation and pancreatic auto-digestion. ${ }^{5}$ Although pancreatic duct obstruction may play an important role in the pathogenesis of gallstone pancreatitis, it is not sufficient to cause the morphological changes of acute pancreatitis, ${ }^{6}$ indicating that other events must occur if the changes induced by pancreatic duct obstruction lead to acute pancreatitis. ossible that pancreatic acinar hyperstimulation, in the presence of duct obstruction, triggers and exacerbates acute pancreatitis. ${ }^{7}$ Probably a common pathogenic pathway that triggers various forms of acute pancreatitis may involve exocrine increased pancreatic hyperstimulation, pancreatic duct pressure, active trypsin reflux, and unregulated activation of trypsin within pancreatic acinar cells. When intracellular protective mechanisms aimed to prevent trypsinogen activation or reduce trypsin activity are overwhelmed, acute pancreatitis occurs.

\section{Pathophysiology of acute pancreatitis}

From experimental studies it has been postulated that acute pancreatitis evolves in 3 phases: ${ }^{7}$ in the first phase, there are intrapancreatic trypsinogen activation and acinar cell injury as a result of release of trypsin; subsequently, there is an intrapancreatic inflammatory reaction that leads to the third phase characterized by development of system inflammatory response syndrome and multiple organ system dysfunction. ${ }^{8}$ Proteolytic enzymes such as trypsin, lipase and phospholipase A, kinins such as bradykinin, cytokines, and other active peptides such as trypsinogen activation peptide and carboxypeptidase activation peptide are liberated from the inflamed pancreas and they transform a single-organ disease into a multisystem disease. ${ }^{8}$ As shown in Figure 1 the pathogenesis and evolution of acute pancreatitis correlate with the clinical phases of the disease. ${ }^{8}$

\section{The experimental evidence}

In experimental animals, myocardium pro-
Correspondence: Raffaele Pezzilli, Pancreas Unit, Department of Digestive System, Sant'OrsolaMalpighi University Hospital, via G. Massarenti 9, 40138 Bologna, Italy.

Tel: +39.051 .1244148 - Fax +39.051 .1244148 .

E-mail: raffaele.pezzilli@aosp.bo.it

Key words: Acute pancreatitis; Cardiac markers; Severity assessment; Acute myocardial infarction.

Conflict of interest: the authors declare no potential conflict of interest.

Received for publication: 25 June 2015 .

Revision received: 22 September 2015.

Accepted for publication: 28 September 2015.

This work is licensed under a Creative Commons Attribution 3.0 License (by-nc 3.0).

(C) Copyright R. Pezzilli et al., 2015

Licensee PAGEPress, Italy

Emergency Care Journal 2015; 11:5397

doi:10.4081/ecj.2015.5397

duces cytokines locally under stress events and IL-6 production is an early event. In addition other cytokines are also produced by the heart and could be correlated with the echocardiographic left ventricular change; for example the production of TNF-alpha occurs in the same period of histological findings as acute myocardial damage, whereas TGF-beta is released in the subsequent period. ${ }^{9}$ In addition, there is experimental evidence in support of the existence of an intrinsic reninangiotensin system in the pancreas. The pancreatic renin-angiotensin system is activated in experimental acute pancreatitis and may cause cardiac and alterations ${ }^{10}$ in humans as well. ${ }^{11}$

\section{The clinical evidence}

Drummond first reported electrocardiographic changes in patients with abdominal pain. ${ }^{12}$ The causes of these alterations were hypothesized due to sympathetic adrenergic activation from a parasympathetic reflex, reduction of intra-cellular potassium, activation of enzymatic systems, reabsorption of toxic substances. ${ }^{13}$ Clinical studies have identified electrocardiographic changes and pericardium alterations due to hemodynamic status. $^{14,15}$ Experimental studies have also reported that in acute pancreatitis there are myocardial ultrastructural disturbances, including interstitial edema and cardiomyocyte hypoxia, ${ }^{16}$ myofiber overcontractility, intercellular edema between the cardiomyocytes, and cardiomyocyte hypertrophy with 
collagenization of myocardial stroma. ${ }^{17}$ The electrocardiographic alterations in acute pancreatitis are various, say tachyarrhythmia or bradyarrhythmias, atrial flutter and atrial fibrillation, supraventricular premature contractions, short PR interval, QRS prolongation, various bundle-branch blocks (such as left and right bundle-branch block, and left anterior hemiblock), non-specific changes in depolarization, decreased T-wave voltage, Twave changes, and ST-segment abnormalities. These alterations are often seen in approximately $50 \%$ of patients. ${ }^{18,19}$ Evaluation of left ventricular function in the early phases of acute pancreatitis has also been investigated, showing an impairment of contractility in a significant portion of patients with acute pancreatitis. ${ }^{20}$ Echocardiographic assessment based on clinical parameters of severity may help to select those patients who merit highly intensive treatment. ${ }^{20}$

\section{The laboratory evidence}

Easy and largely available serum markers are required to rapidly identify those patients having a cardiac involvement during the course of acute pancreatitis. ${ }^{21}$ In a recent study, we evaluated the presence of elevated levels of high-sensitivity cardiac Troponin (hs-TnT) in patients with acute pancreatitis, ${ }^{22}$ and we found that more than $35 \%$ of them had high serum levels of this cardiac marker. The time course of serum troponin T in the early phases of acute pancreatitis is reported in Figure 2. ${ }^{22}$ However, the absence of any clinical and electrocardiographic features of acute coronary syndrome in our patients suggests that abnormally high results should be interpreted as of nonischemic origin. ${ }^{23,24}$ In conclusion, we believe that troponin I should be used in assessing cardiac damage in acute pancreatitis patients, but additional studies exploring this possibility are needed.

\section{The future way}

Other markers of cardiac damage should be evaluated in clinical practice for a more in-depth evaluation of cardiac involvement in acute pancreatitis of different severity. For example, arginine vasopressin (AVP) also known as antidiuretic hormone (ADH) is one of the key hormones for cardiovascular homeostasis. Despite its pivotal role in cardiovascular diseases, both the measurement and the diagnostic use of AVP have never reached clinical practicability due to the technical problems related mainly to three reasons: its short plasma half-life, its interaction with platelets in the serum, and its small circulating quantity. Another interesting molecule to test in clinical practice is copeptin, a glycosylated 39-amino acid long peptide with a leucine-rich core segment..$^{25}$ Copeptin and AVP share the same precursor peptide, the 164-amino acid long preprovasopressin and copeptin is the C-terminal part of pro-AVP (CT-pro-AVP) and it is released together with
AVP during precursor processing. In contrast to AVP, copeptin is very stable in serum or plasma at room temperature, and is easy to measure. In contrast to many other biomarkers, the copeptin plasma concentration was similar in different age groups and showed no correlation with age. A particularly interesting observation was the response of circulating copeptin levels as a result of an acute myocardial infarction ${ }^{26}$ since these protein

\begin{tabular}{|c|c|c|c|c|c|}
\hline PHASE & INITIAL & EARLY & MIDDLE & \multicolumn{2}{|c|}{ LATE } \\
\hline TIMING & Hours & 1st week & 2nd week & \multicolumn{2}{|c|}{ 3rd-4th week } \\
\hline $\begin{array}{l}\text { MAJOR } \\
\text { EVENTS }\end{array}$ & $\begin{array}{c}\text { Altered } \\
\text { intra-acinar } \\
\text { protein traffic } \\
\text { Accumulation } \\
\text { of trypsinogen } \\
\text { in the interstitial } \\
\text { space }\end{array}$ & $\begin{array}{l}\text { Innapropriate } \\
\text { activation } \\
\text { of proteases }\end{array}$ & & $\begin{array}{l}\text { Gut an } \\
\text { bac }\end{array}$ & ay \\
\hline DEATHS & ? & $32 \%$ & $12 \%$ & $19 \%$ & $37 \%$ \\
\hline CAUSES & & & & & \\
\hline $\begin{array}{l}\text { Multiple } \\
\text { organ } \\
\text { failure }\end{array}$ & ? & $26 \%$ & $0 \%$ & $0 \%$ & $0 \%$ \\
\hline Infection & ? & $0 \%$ & $5 \%$ & $12 \%$ & $28 \%$ \\
\hline
\end{tabular}

Figure 1. Pathophysiology of acute pancreatitis.

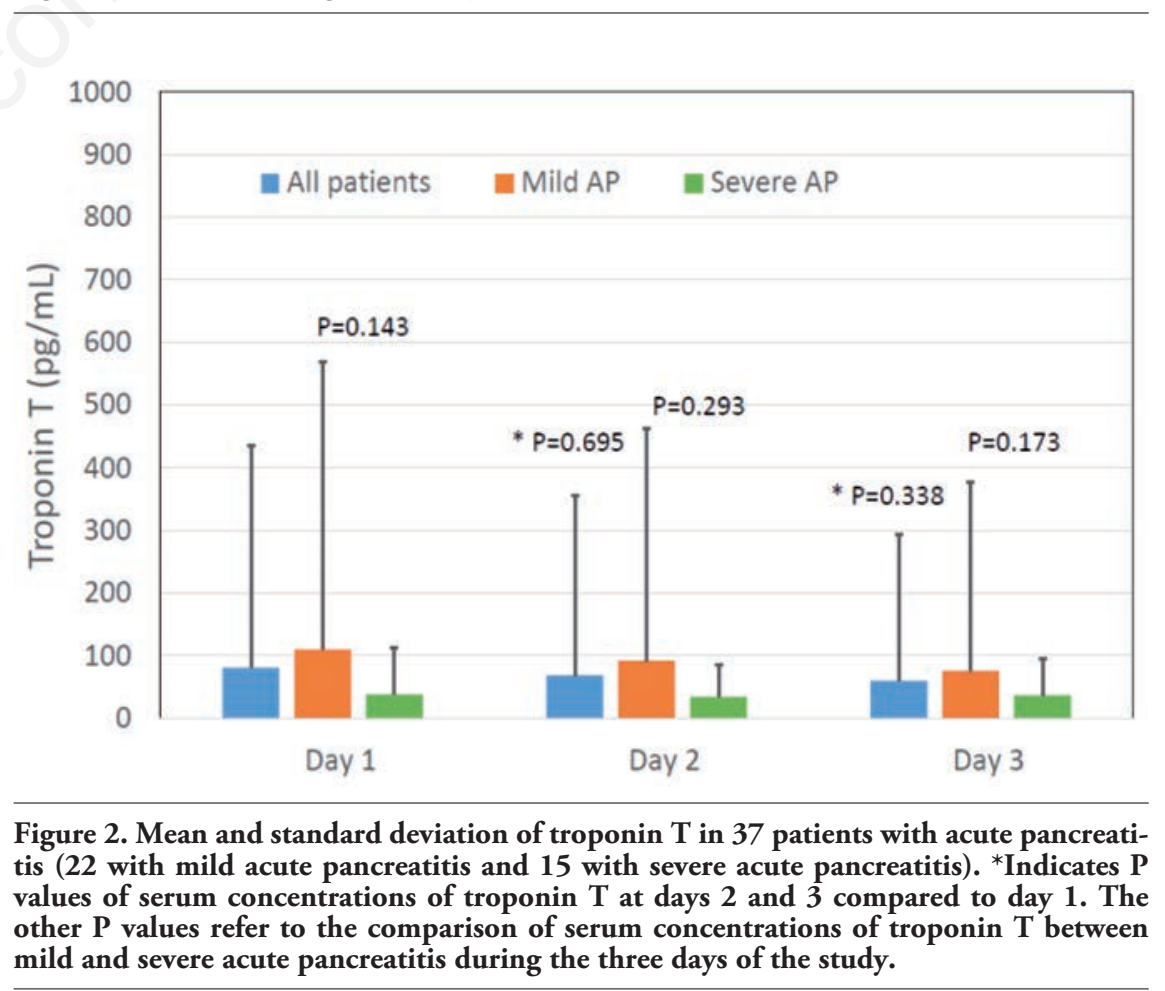


levels were higher in patients who died or were readmitted with heart failure as compared to event-free survivors. Thus, the measurement of plasma copeptin should be investigated in acute pancreatitis patients in order to select those who require more intensive support.

Finally, adrenomedullin (ADM), a 52amino-acid peptide elevated in plasma of patients having heart failure and/or postacute coronary syndrome, has been isolated in human pheochromocytoma and it is also present in the heart, brain, lung, kidney and gastrointestinal organs; it has a potent vasodilator activity due to an increase in cyclic adenosine monophosphate levels. ${ }^{27}$ It should be underlined that the quantification of ADM is quite difficult due to a short halflife and the lack of the reliable laboratory techniques. The identification of mid-regional pro-adrenomedullin (MR-proADM) ${ }^{28,29}$ has overcome these problems, because it is a stable peptide possibly reflecting the concentration of ADM. MR-proADM is probably secreted in equimolar amounts to those of ADM, and it does not have any physiological effects which might explain its apparent stability. Plasma MR-proADM concentrations predict an adverse outcome in patients in the recovery phase of myocardial infarction and appear to add information beyond the strong predictor N-Terminal pro-B-Type natriuretic peptide (NT-proBNP). There are no studies on the ADM circulating concentration in acute pancreatitis patients and this topic should be explored in order to obtain more accurate information regarding cardiac involvement in acute pancreatitis. In any way, it has been recently reported that MRproADM is a strong predictor of rehospitalization and mortality in patients with septic shock $^{28,30}$ and we believe that this molecule may have a practical role in patients with infected pancreatic necrosis. Regarding NTproBNP, we have found that this molecule is abnormally elevated in acute pancreatitis and its elevation persists for at least 72 hours (Figure 3). In addition, similar high levels of serum NT-proBNP are present in patients with mild acute pancreatitis as well as in those with severe disease. ${ }^{22}$ Thus, we should be aware that elevated values of NT-proBNP in patients with acute pancreatitis cannot be useful to detect hearth failure.

\section{Conclusions}

The exact mechanism of myocardial injury during the course of acute pancreatitis still remains unclear. In clinical practice, laboratory examinations are needed to distinguish in the emergency room patients with epigastric pain having acute pancreatitis from those with acute myocardial infarction because the treatment strategy of the two diseases differs markedly. In addition, further efforts should be

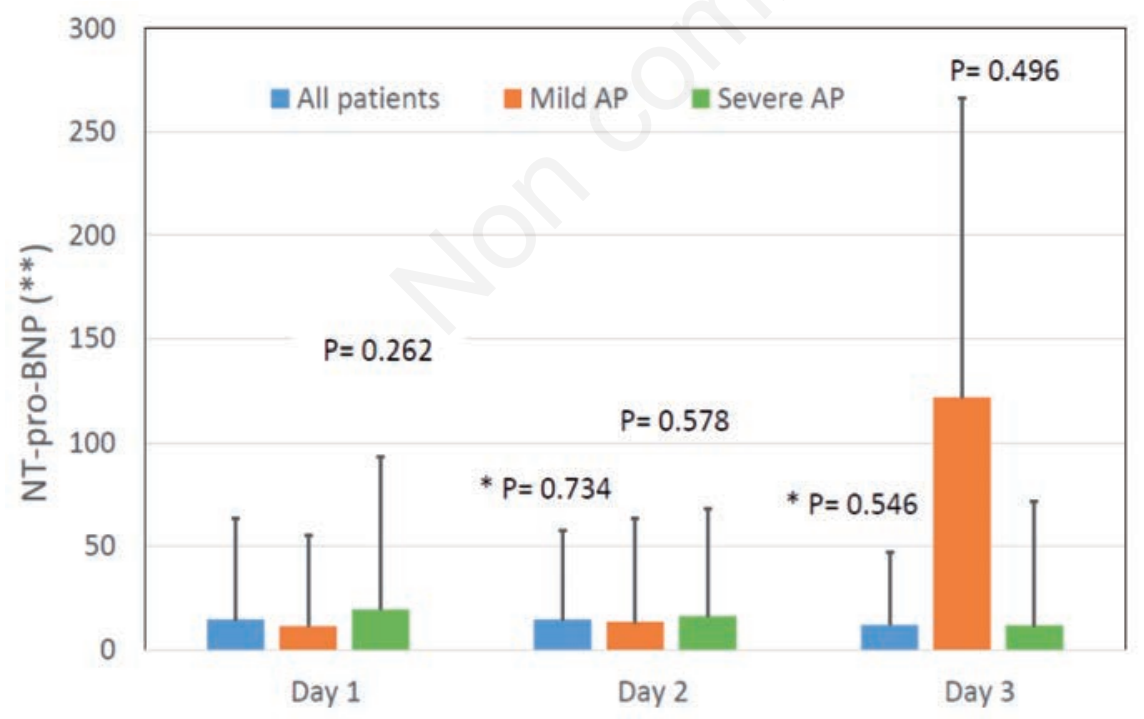

Figure 3. Mean and standard deviation of NT-pro-BNP in 37 patients with acute pancreatitis (22 with mild acute pancreatitis and 15 with severe acute pancreatitis). ${ }^{* *}$ Indicates normalized values of NT-pro-BNP: values from 0 to 1 represent values within the reference range, and values greater than 1 represent values above the upper reference limit. *Indicates $P$ values of serum concentrations of troponin $T$ at days 2 and 3 compared to day 1 . The other $P$ values refer to the comparison of serum concentrations of troponin $T$ between mild and severe acute pancreatitis during the three days of the study. made to identify acute pancreatitis patients at high risk of cardiovascular disease and the new above-mentioned markers need to be explored for their possible use in clinical practice.

\section{References}

1. Uomo G. La pancreatite acuta in Italia. Studio osservazionale su 1005 casi. Firenze, Italy: Press Service; 2001.

2. Pezzilli R, Bellacosa L, Barakat B. Abdominal pain and ECG alteration: a simple diagnosis? Adv Med Sci 2010;55:333-6.

3. Swaminathan R. Magnesium metabolism and its disorders. Clin Biochem Rev 2003;24:47-66.

4. Pezzilli R, Uomo G, Gabbrielli A, et al. A prospective multicentre survey on the treatment of acute pancreatitis in Italy. Digest Liver Dis 2007;39:838-46.

5. Saluja A, Saluja M, Villa A, et al. Pancreatic duct obstruction in rabbits causes digestive zymogen and lysosomal enzyme colocalization. J Clin Invest 1989;84:1260-6.

6. Meyerholz DK, Samuel I. Morphologic characterization of early ligationinduced acute pancreatitis in rats. Am J Surg 2007;194:652-8.

7. Pezzilli R. Pharmacotherapy for acute pancreatitis. Expert Opin Pharmaco 2009;10:2999-3014.

8. Pezzilli R, Fantini L, Morselli-Labate AM. New approaches for the treatment of acute pancreatitis. JOP 2006;7:79-91.

9. Meyer A, Kubrusly MS, Salemi VM, et al. Severe acute pancreatitis: a possible role of intramyocardial cytokine production. JOP 2014;15:237-42.

10. Leung PS. Local renin-angiotensin system in the pancreas: the significance of changes by chronic hypoxia and acute pancreatitis. JOP 2001;2:3-8.

11. Pezzilli R, Fantini L. Proteases of the renin-angiotensin system in human acute pancreatitis. In: Leung PS, ed. Frontiers in research of the reninangiotensin system on human disease. Amsterdam, Netherlands: Springer; 2007. pp 55-71.

12. Drummond J. Cardiac abnormalities of abdominal origin. $\mathrm{S}$ Afr Med J 1934;8:520-6.

13. Tullio D, Staniscia GC, Di Bartolomeo A, Paolucci A. Electrocardiographic changes in acute abdomen. Minerva Med 1981;72:1951-8.

14. Gullo L, Labriola E, Di Benedetto S, et al. Acute pancreatitis associated with paroxysmal atrial fibrillation. A case report. 
Panminerva Med 1988;30:111-3.

15. Di Carlo V, Nespoli A, Chiesa R, et al. Hemodynamic and metabolic impairment in acute pancreatitis. World J Surg 19815:329-39.

16. Banks PA. Epidemiology, natural history, and predictors of disease outcome in acute and chronic pancreatitis. Gastrointest Endosc 2002;56:26-30.

17. Saulea A, Costin S, Rotari V. Heart ultrastructure in experimental acute pancreatitis. Rom J Phys 1997;34:35-44.

18. Pezzilli R, Barakat B, Billi P, Bertaccini B. Electrocardiographic abnormalities in acute pancreatitis. Eur J Emerg Med 1999;6:27-9.

19. Rubio-Tapia A, García-Leiva J, AsensioLafuente E, et al. Electrocardiographic abnormalities in patients with acute pancreatitis. J Clin Gastroenterol 2005; 39: 815-8.

20. Pezzilli R, Billi P, Bertaccini B, Gullo L. Pericardial effusion and left ventricular function in acute pancreatitis. Am J Gastroenterol 1996;91:997-1000.

21. Pezzilli R, Barassi A, Iammarino MT, Melzi d'Eril GV. Is troponin T a useful marker of myocardial damage in acute pancreatitis? A prospective time course study. Digest Liver Dis 2013;45:347-8.

22. Barassi A, Pezzilli R, Romanelli MC, et al. Serum markers of myocardial damage in acute pancreatitis: a prospective time course study. Pancreas 2015;44:678-80.

23. Pezzilli R, Billi P, Cappelletti 0, Barakat $\mathrm{B}$, et al. Rhabdomyolysis and acute pancreatitis. J Gastroen Hepatol 1999;14:168-71.

24. Casagranda I, Cavazza M, Clerico A, et al. Proposal for the use in emergency departments of cardiac troponins measured with the latest generation methods in patients with suspected acute coronary syndrome without persistent STsegment elevation. Clin Chem Lab Med 2013;51:1727-37.

25. Holwerda DA. A glycopeptide from the posterior lobe of pig pituitaries.Isolation and characterization. Eur J Biochem 1972;28:334-9.

26. Khan SQ, Dhillon OS, O'Brien RJ, et al. C-terminal provasopressin (copeptin) as a novel and prognostic marker in acute myocardial infarction: Leicester Acute Myocardial Infarction Peptide (LAMP) study. Circulation 2007;115:2103-10.
27. Asakawa H, Nishikimi T, Suzuki T, et al. Elevation of two molecular forms of adrenomedullin in plasma and urine in patients with acute myocardial infarction treated with early coronary angioplasty. Clin Sci 2001;100:117-26.

28. Pezzilli R, Barassi A, Pigna A, et al. Time course of proadrenomedullin in the early phase of septic shock. A comparative study with other proinflammatory proteins. Panminerva Med 2012;54:211-7.

29. Palladini G, Barassi A, Perlini S, et al. Midregional proadrenomedullin (MRproADM) is a powerful predictor of early death in $\mathrm{AL}$ amyloidosis. Amyloid 2011;18:216-21.

30. Travaglino F, Russo V, De Berardinis B, et al. Thirty and ninety days mortality predictive value of admission and in-hospital procalcitonin and mid-regional proadrenomedullin testing in patients with dyspnea. Results from the VERyfing DYspnea trial. Am J Emerg Med 2014;32: $334-41$. 